\title{
Symptom Burden in Patients With Reduced Performance Status at the Start of Palliative Radiotherapy
}

\author{
CARSTEN NIEDER ${ }^{1,2}$ and THOMAS A. KÄMPE ${ }^{1}$ \\ ${ }^{1}$ Department of Oncology and Palliative Medicine, Nordland Hospital, Bod $\phi$, Norway; \\ ${ }^{2}$ Department of Clinical Medicine, Faculty of Health Sciences, University of Troms $\phi$, Troms $\phi$, Norway
}

\begin{abstract}
Background/Aim: Previous research has suggested that palliative radiotherapy is a useful measure, unless short survival reduces the time spent without active treatment, and in the case of a low likelihood of experiencing a net benefit in quality of life. Patients with reduced performance status (PS) may be especially at risk of futile treatment, despite having a relatively high symptom burden and thus a potential benefit. Therefore, we analyzed the symptom burden of patients with Eastern Cooperative Oncology Group (ECOG) PS 3-4 in our center. Patients and Methods: A retrospective study was performed of 102 consecutive patients who received palliative radiotherapy for different indications. The Edmonton Symptom Assessment Scale (ESAS) was employed to assess the pre-radiotherapy symptoms. Results: When applying the lowest threshold (ESAS $\geq 1$ ), up to $97 \%$ of patients with PS 3-4 reported symptoms, such as fatigue and dry mouth. When focusing on moderate/severe symptoms $(E S A S \geq 4)$, still up to $77 \%$ of patients with PS 3-4 reported such a burden. The largest differences between patients with PS 3-4 and those with 0-1 were seen with regard to nausea, fatigue, dry mouth and reduced appetite. The median survival of patients with PS 34 was 2 months. Conclusion: Given that many of the symptoms reported by patients with PS 3-4 tend to worsen temporarily after radiotherapy, patients with short survival may not experience a net benefit during the few weeks before death. However, if other symptoms such as dyspnea or pain prevail, short-course radiotherapy may result in worthwhile palliation and should, therefore, be considered on a case-bycase basis and after estimation of the remaining lifespan.
\end{abstract}

This article is freely accessible online.

Correspondence to: Carsten Nieder, Department of Oncology and Palliative Medicine, Nordland Hospital, 8092 Bodø, Norway. Tel: +47 75578449, Fax: +47 75534975, e-mail: carsten.nieder@nlsh.no

Key Words: Radiotherapy, cancer, palliative treatment, performance status, symptom score.
Common indications for palliative radiotherapy include pain, dyspnea and other thoracic symptoms, and neurological complaints (1). Both primary tumors and nodal or other metastatic lesions may be the cause of these symptoms (2). It is prudent to quantify quality of life and symptom burden, as well as performance status (PS) at the time of each patient's initial clinical appointment $(3,4)$. In addition, survival time should be estimated, e.g. on the basis of validated prognostic scores or nomograms, in order to avoid a mismatch between treatment intensity and duration, or resource utilization, on one hand and the benefit and remaining lifespan on the other hand (5-7). One of the established tools that have been implemented by several oncology care providers is the Edmonton Symptom Assessment System (ESAS) (8-14). This short, one-sheet questionnaire addresses major symptoms and wellbeing on a numeric scale of 0-10 (highest symptom severity 10), including pain, nausea, dyspnea, depression and others. In oncology, reduced PS is often caused by advanced disease and large tumor burden, which in turn is likely to result in worse quality of life and symptom severity $(15,16)$. Due to these considerations, we performed a retrospective study addressing the symptom severity in patients with reduced PS who started palliative radiotherapy at our Institution.

\section{Patients and Methods}

The study included 102 patients at an academic teaching hospital who received palliative radiotherapy during the time period 20132015, as already described (10). The ESAS tool was administered by a registered oncology nurse immediately before oncologist consultation and imaging for treatment planning, i.e. approximately 1 week before palliative radiotherapy. At the same day, the oncologist recorded the patient's PS according to the Eastern Cooperative Oncology Group (ECOG) scale (0=best PS). All medical records were available in the hospital's electronic patient record system. Baseline characteristics, treatment and date of death or last contact were abstracted. Statistical analysis was performed with IBM SPSS Statistics 26 (IBM Corp., Armonk, NY, USA). Three subgroups were analyzed stratified for ECOG PS (0 and 1 combined; 2; 3 and 4 combined). The severity of each ESAS symptom was classified as present (score 1-10) and moderate/severe 
(score 4-10), in accordance with previously reported methods (17). We employed the chi-square test (when appropriate, Fisher exact probability test or $t$-test). A $p$-value of 0.05 or less was considered statistically significant. Two-tailed tests were performed. Actuarial survival from the start of radiotherapy was analyzed with the Kaplan-Meier method and the log-rank test. Ethical approval was not required for this secondary analysis of the database, in accordance with national and institutional guidelines.

\section{Results}

The baseline characteristics of the study population are shown in Table I. The three subgroups with good (0-1), intermediate (2) and poor (3-4) ECOG PS had comparable median age (69.5-71 years, $\mathrm{p}>0.2)$. All 30 patients with poor ECOG PS scored at least one ESAS symptom as moderate/severe (score 4-10), compared to 33 out of 38 patients with good ECOG PS $(p=0.06)$. As shown in Table II, not all ESAS items contributed to these differences. Patients with poor ECOG PS had significantly higher rates of moderate/severe nausea, fatigue, dry mouth, pain in activity and reduced appetite. Table III shows the results for ESAS symptom severity 1-10, which did not differ greatly from those displayed in Table II, except for outcomes that are not the focus of the present evaluation. Interestingly, patients with poor ECOG PS did not report greater problems with anxiety, sadness and depression compared to those with better PS.

Four out of 30 patients (13\%) with ECOG PS 3-4 did not complete their prescribed course of radiotherapy compared to only one patient with PS 0-2. Median overall survival was 2 months for those with PS 3-4, 3.7 months for those with PS 2 and 11.7 months for those with PS 0-1 $(p=0.0001)$.

\section{Discussion}

Palliative radiotherapy has evolved into a highly individualized treatment concept, which provides symptom palliation and, in selected patients, improves overall survival $(1,6,18,19)$. However, the management of patients with reduced PS (ECOG 3-4) is among several unsolved problems. Often these patients survive for a few months only (sometimes few weeks) and thus prolonged courses of radiotherapy, which have the potential to cause clinically relevant side-effects, are not well tailored to their goals of care. Careful evaluation of prognosis and symptom burden is recommended in order to personalize radiotherapy, or select other, simpler palliative options, for this vulnerable population. Inspired by other clinicians $(3,14)$, our group has elected to adopt the ESAS scale as a pre-radiotherapy evaluation tool. In the present study, we evaluated the symptom burden reported by patients with ECOG PS 3-4. When applying the lowest threshold $(\mathrm{ESAS} \geq 1)$, it is evident that up to $97 \%$ of patients reported symptoms, such as
Table I. Baseline characteristics before palliative radiotherapy in 102 patients.

\begin{tabular}{|c|c|}
\hline Variable & Value \\
\hline \multicolumn{2}{|c|}{ ECOG performance status, n (\%) } \\
\hline 0 & $15(15)$ \\
\hline 1 & $23(23)$ \\
\hline 2 & $34(33)$ \\
\hline 3 or 4 & $30(29)$ \\
\hline \multicolumn{2}{|l|}{ Gender, n (\%) } \\
\hline Male & $75(74)$ \\
\hline Female & $27(26)$ \\
\hline \multicolumn{2}{|l|}{ Primary tumor site, $\mathrm{n}(\%)$} \\
\hline Prostate & $31(30)$ \\
\hline Breast & $12(12)$ \\
\hline Lung (small cell) & $2(2)$ \\
\hline Lung (non-small cell) & $26(25)$ \\
\hline Colorectal & $5(5)$ \\
\hline Bladder & $5(5)$ \\
\hline Malignant melanoma & $4(4)$ \\
\hline Kidney & $4(4)$ \\
\hline Other & $13(13)$ \\
\hline \multicolumn{2}{|l|}{ RT target type, $\mathrm{n}(\%)^{\mathrm{a}}$} \\
\hline Bone metastases & $63(62)$ \\
\hline Brain metastases & $13(13)$ \\
\hline Lymph node metastases & $6(6)$ \\
\hline Lung or thorax & $14(14)$ \\
\hline Prostate & $4(4)$ \\
\hline Other & $15(15)$ \\
\hline \multicolumn{2}{|c|}{ Systemic cancer treatment, n (\%) } \\
\hline No & $49(48)$ \\
\hline Before RT & $53(52)$ \\
\hline \multicolumn{2}{|c|}{ Time from first cancer diagnosis to RT, months } \\
\hline Mean \pm SD & $53 \pm 16$ \\
\hline \multicolumn{2}{|c|}{ Time from first metastasis (if any) to RT, months } \\
\hline Mean \pm SD & $27 \pm 7$ \\
\hline
\end{tabular}

ECOG: Eastern Cooperative Oncology Group; RT: radiotherapy. ${ }^{a}$ More than one possible in the same patient.

fatigue and dry mouth (Table III). In addition to these two, dyspnea and reduced appetite were significantly more common in these patients compared to those with PS 0-1. When focusing on moderate/severe symptoms $(\mathrm{ESAS} \geq 4)$, still up to $77 \%$ of patients with PS 3-4 reported such burden (Table II). The largest differences compared with patients with PS 0-1 were seen with regard to nausea, fatigue, dry mouth and reduced appetite. Unfortunately, radiotherapy may cause dose- and anatomical site-dependent temporary deterioration of nausea, fatigue and appetite. Therefore, patients with short survival may not experience the benefits of radiotherapy, while those with longer survival eventually recover from the side-effects and enjoy a phase of symptom control, e.g. freedom from bone pain, and improved quality of life. The net balance between improvement and toxicityrelated deterioration is difficult to estimate without preradiotherapy symptom evaluation. 
Table II. Edmonton Symptom Assessment Scale (ESAS) score before palliative radiotherapy in 102 patients. Data are the percentage of patients with moderate/severe symptoms (score $\geq 4$ ).

\begin{tabular}{|c|c|c|c|c|c|c|c|c|c|c|c|c|}
\hline \multirow{3}{*}{$\begin{array}{l}\text { Performance } \\
\text { status }\end{array}$} & \multicolumn{11}{|c|}{ Symptom } & \multirow{3}{*}{$\begin{array}{c}\text { Overall } \\
\text { well-being }\end{array}$} \\
\hline & \multirow[t]{2}{*}{ Dyspnea } & \multirow[t]{2}{*}{ Appetite } & \multirow{2}{*}{$\begin{array}{c}\text { Dry } \\
\text { mouth }\end{array}$} & \multirow{2}{*}{$\begin{array}{c}\mathrm{Sad} / \\
\text { depressed }\end{array}$} & \multirow[t]{2}{*}{ Anxious } & \multicolumn{2}{|c|}{ Pain } & \multirow[t]{2}{*}{ Constipation } & \multirow[t]{2}{*}{ Fatigue } & \multirow{2}{*}{$\begin{array}{l}\text { Poor } \\
\text { sleep }\end{array}$} & \multirow[t]{2}{*}{ Nausea } & \\
\hline & & & & & & On activity & At rest & & & & & \\
\hline $0-1$ & 26 & 37 & 21 & 18 & 32 & 42 & 32 & 26 & 37 & 49 & 0 & 42 \\
\hline 2 & 47 & 50 & 41 & 32 & 42 & 68 & 50 & 33 & 68 & 33 & 9 & 64 \\
\hline $3-4$ & 40 & 77 & 70 & 30 & 27 & 73 & 43 & 30 & 77 & 23 & 30 & 64 \\
\hline p-Value & $>0.05$ & 0.004 & 0.0003 & $>0.05$ & $>0.05$ & 0.02 & $>0.05$ & $>0.05$ & 0.002 & $>0.05$ & 0.0002 & $>0.05$ \\
\hline
\end{tabular}

Table III. Edmonton Symptom Assessment Scale (ESAS) score before palliative radiotherapy in 102 patients. Data are the percentage of patients with any symptom (score $\geq 1$ ).

\begin{tabular}{|c|c|c|c|c|c|c|c|c|c|c|c|c|}
\hline \multirow{3}{*}{$\begin{array}{l}\text { Performance } \\
\text { status }\end{array}$} & \multicolumn{11}{|c|}{ Symptom } & \multirow{3}{*}{$\begin{array}{c}\text { Overall } \\
\text { well-being }\end{array}$} \\
\hline & \multirow[t]{2}{*}{ Dyspnea } & \multirow[t]{2}{*}{ Appetite } & \multirow{2}{*}{$\begin{array}{c}\text { Dry } \\
\text { mouth }\end{array}$} & \multirow{2}{*}{$\begin{array}{c}\mathrm{Sad} / \\
\text { depressed }\end{array}$} & \multirow[t]{2}{*}{ Anxious } & \multicolumn{2}{|c|}{ Pain } & \multirow[t]{2}{*}{ Constipation } & \multirow[t]{2}{*}{ Fatigue } & \multirow{2}{*}{$\begin{array}{l}\text { Poor } \\
\text { sleep }\end{array}$} & \multirow[t]{2}{*}{ Nausea } & \\
\hline & & & & & & On activity & At rest & & & & & \\
\hline $0-1$ & 42 & 50 & 39 & 53 & 55 & 74 & 58 & 45 & 61 & 70 & 26 & 76 \\
\hline 2 & 74 & 76 & 65 & 56 & 64 & 85 & 71 & 58 & 88 & 61 & 38 & 85 \\
\hline $3-4$ & 70 & 87 & 97 & 47 & 50 & 83 & 70 & 60 & 97 & 53 & 53 & 86 \\
\hline p-Value & 0.01 & 0.003 & 0.00001 & $>0.05$ & $>0.05$ & $>0.05$ & $>0.05$ & $>0.05$ & 0.0004 & $>0.05$ & 0.08 & $>0.05$ \\
\hline
\end{tabular}

Like other previous retrospective studies, the present one is mainly hypothesis-generating and in addition hampered by the limited number of patients. No longitudinal follow-up of ESAS after radiotherapy or patient-reported decision regret was available. Bradley et al. reported a comparable ESAS study in patients managed with palliative radiotherapy (20). They found that patients with poorer PS (Karnofsky PS $\leq 60$ ) had significantly higher symptom scores for all symptoms. However, mean scores were compared, meaning that the statistical methods were not identical. A later study by the same research group confirmed that worse well-being was associated with lower Karnofsky PS (14). This study included analyses with categorical scores, as did our study, which showed numerical differences (Tables II and III, ESAS item 12) pointing in the same direction. However, these differences were not statistically significant.

Because many of the symptoms reported by patients with PS 3-4 tend to worsen temporarily after radiotherapy, patients with short survival may not experience a net benefit during the few weeks before death. However, if other symptoms prevail, short-course radiotherapy may result in worthwhile palliation and should therefore be considered on a case-by-case basis and after estimation of the remaining lifespan.

\section{Conflicts of Interest}

The Authors declare that they have no conflicts of interest.

\section{Authors' Contributions}

CN participated in the design of the study and performed the statistical analysis. TAK collected patient data. CN, and TAK conceived the study and drafted the article. All Authors read and approved the final article.

\section{References}

1 Razvi Y, Chan S, Zhang L, Tsao M, Barnes E, Danjoux C, Sousa P, Zaki P, McKenzie E, DeAngelis C and Chow E: A review of the Rapid Response Radiotherapy Program in patients with advanced cancer referred for palliative radiotherapy over two decades. Support Care Cancer 27(6): 2131-2134, 2019. PMID: 30246224. DOI: 10.1007/s00520-018-4474-9

2 Nieder C, Haukland E, Mannsåker B, Pawinski A and Dalhaug A: Early palliative radiation therapy in patients with newly diagnosed cancer: Reasons, clinical practice, and survival. Pract Radiat Oncol 5(5): e537-e542, 2015. PMID: 25823382. DOI: 10.1016/j.prro.2015.02.008

3 Fan G, Hadi S and Chow E: Symptom clusters in patients with advanced-stage cancer referred for palliative radiation therapy 
in an outpatient setting. Support Cancer Ther 4: 157-162, 2007. PMID: 18632482. DOI: 10.3816/SCT.2007.n.010

4 McDonald R, Chow E, Rowbottom L, Bedard G, Lam H, Wong E, Popovic M, Pulenzas N and Tsao M: Quality of life after palliative radiotherapy in bone metastases: A literature review. $\mathrm{J}$ Bone Oncol 4(1): 24-31, 2014. PMID: 26579481. DOI: 10.1016/ j.jbo.2014.11.001

5 Rades D, Dziggel L, Manig L, Janssen S, Khoa MT, Duong VN, Khiem VH and Schild SE: Predicting survival after whole-brain irradiation for cerebral metastases in patients with cancer of the bladder. In Vivo 32(3): 633-636, 2018. PMID: 29695570. DOI: 10.21873/invivo.112285

6 Nieder C, Tollali T, Yobuta R, Reigstad A, Flatoy LR and Pawinski A: Palliative thoracic radiotherapy for lung cancer: What is the impact of total radiation dose on survival? J Clin Med Res 9(6): 482-487, 2017. PMID: 28496548. DOI: $10.14740 /$ jocmr $2980 \mathrm{w}$

7 Nieder C, Angelo K, Dalhaug A, Pawinski A, Haukland E and Norum J: Palliative radiotherapy during the last month of life: Predictability for referring physicians and radiation oncologists. Oncol Lett 10(5): 3043-3049, 2015. PMID: 26722287. DOI: 10.3892/ol.2015.3656

8 Bruera E, Kuehn N, Miller MJ, Selmser P and Macmillan K: The Edmonton Symptom Assessment System (ESAS): A simple method for the assessment of palliative care patients. J Palliat Care 7: 6-9, 1991. PMID: 1714502.

9 Zeng L, Zhang L, Culleton S, Jon F, Holden L, Kwong J, Khan L, Tsao M, Danjoux C, Sahgal A, Barnes E and Chow E: Edmonton Symptom Assessment Scale as a prognosticative indicator in patients with advanced cancer. J Palliat Med 14(3): 337-342, 2011. PMID: 21254813. DOI: 10.1089/jpm.2010.0438

10 Nieder C and Kämpe TA: Contribution of patient-reported symptoms before palliative radiotherapy to development of multivariable prognostic models. Anticancer Res 38(3): 17051709, 2018. PMID: 29491105.

11 Nieder C and Kämpe TA: Does marital status influence levels of anxiety and depression before palliative radiotherapy? In Vivo 32(2): 327-330, 2018. PMID: 29475916. DOI: 10.21873/ invivo.11241

12 Nieder C, Dalhaug A, Haukland E and Engljähringer K: Patientreported symptom burden, rate of completion of palliative radiotherapy and 30-day mortality in two groups of cancer patients managed with or without additional care by a multidisciplinary palliative care team. Anticancer Res 38: 22712275, 2018. PMID: 29599349.
13 Khan L, Kwong J, Nguyen J, Chow E, Zhang L, Culleton S, Zeng L, Jon F, Tsao M, Barnes E, Danjoux C, Sahgal A and Holden L: Comparing baseline symptom severity and demographics over two time periods in an outpatient palliative radiotherapy clinic. Support Care Cancer 20(3): 549-555, 2012. PMID: 21360036. DOI: 10.1007/s00520-011-1120-1

14 Lien K, Zeng L, Zhang L, Nguyen J, Di Giovanni J, Popovic M, Jamani R, Cramarossa G, Culleton S and Chow E: Predictive factors for well-being in advanced cancer patients referred for palliative radiotherapy. Clin Oncol 24(6): 443-451, 2012. PMID: 22794326. DOI: $10.1016 /$ j.clon.2012.01.004

15 Carmichael JA, Wing-San Mak D and O'Brien M: A review of recent advances in the treatment of elderly and poor performance NSCLC. Cancers 10(7): E236, 2018. PMID: 30021993. DOI: 10.3390/cancers 10070236

16 Nieder C, Guckenberger M, Gaspar LE, Rusthoven CG, De Ruysscher D, Sahgal A, Nguyen T, Grosu AL and Mehta MP: Management of patients with brain metastases from non-small cell lung cancer and adverse prognostic features: Multi-national radiation treatment recommendations are heterogeneous. Radiat Oncol 14(1): 33, 2019. PMID: 30770745. DOI: 10.1186/s13014019-1237-9

17 McKenzie E, Zhang L, Chan S, Zaki P, Razvi Y, Tsao M, Barnes E, Drost L, Yee C, Hwang M, DeAngelis C and Chow E: Symptom correlates of dyspnea in advanced cancer patients using the Edmonton Symptom Assessment System. Support Care Cancer 28(1): 87-98, 2020. PMID: 30982093. DOI: 10.1007/ s00520-019-04787-0

18 Nieder C, Yobuta R and Mannsåker B: Patterns of treatment and outcome in patients with 20 or more brain metastases. In Vivo 33(1): 173-176, 2019. PMID: 30587619. DOI: 10.21873/invivo. 11455

19 Tey J, Soon YY, Cheo T, Ooi KH, Ho F, Vellayappan B, Chia D and Tai BC: Efficacy of palliative bladder radiotherapy for hematuria in advanced bladder cancer using contemporary radiotherapy techniques. In Vivo 33(6): 2161-2167, 2019. PMID: 31662552. DOI: 10.21873 /invivo. 11718

20 Bradley N, Davis L and Chow E: Symptom distress in patients attending an outpatient palliative radiotherapy clinic. J Pain Symptom Manage 30(2): 123-131, 2005. PMID: 16125027. DOI: $10.1016 /$ j.jpainsymman.2005.02.015

Received December 17, 2019

Revised January 7, 2020

Accepted January 8, 2020 